\title{
Evaluation and validation of the suitable control genes for quantitative PCR studies in plasma DNA for non-invasive prenatal diagnosis
}

\author{
QIWEI YANG ${ }^{1,2}$, HASSAN ABDELLAH AHMED ALI ${ }^{1,2}$, SHAN YU $^{1,2}$, LIN ZHANG $^{1,2}$, \\ XIUYING $\mathrm{LI}^{2}$, ZHENWU DU ${ }^{1-3}$ and GUIZHEN ZHANG ${ }^{1-3}$ \\ ${ }^{1}$ Central Laboratory, Second Hospital, Jilin University, Jilin, Changchun $130041 ;{ }^{2}$ China-Japan Union Hospital, \\ Jilin University, Jilin, Changchun 130033; ${ }^{3}$ Orthopaedic Institute, Second Hospital, Jilin University, \\ Jilin, Changchun 130041, P.R. China
}

Received March 27, 2014; Accepted September 9, 2014

DOI: $10.3892 / \mathrm{ijmm} .2014 .1944$

\begin{abstract}
Quantitative polymerase chain reaction (qPCR) is widely used in quantitation of plasma DNA for non-invasive prenatal diagnosis (NIPD). Control genes are indispensable as standard normalizers in qPCR analysis, and there is increasing evidence indicating that the content levels of commonly used control genes vary significantly in different independent experiments. The commonly used control genes for DNA quantitation using qPCR in plasma DNA analysis are frequently chosen without any preliminary evaluation of their suitability. The present study aimed to examine a panel of six common control genes (HBB, TERT, GAPDH, ALB, ACTB and TRG) in order to evaluate and validate the most reliable control genes for qPCR studies in the quantitation of plasma DNA from pregnant and non-pregnant females for NIPD. Plasma DNA was extracted from the peripheral blood of 18 pregnant females and 18 non-pregnant females by the QIAamp DNA mini kit. qPCR followed by geNorm, NormFinder and BestKeeper based analysis was conducted to evaluate the DNA content stabilities of the six candidate control genes. DSCR 3 was used to validate the result. The study recommended TERT and the combination of ACTB and TERT as the optimal control genes for qPCR studies on pregnant/non-pregnant plasma DNA quantitation. Thus, the study reveals that the DNA content stability of widely used control genes varies significantly in pregnant and non-pregnant plasma DNA.
\end{abstract}

Correspondence to: Professor Guizhen Zhang or Dr Zhenwu Du, Central Laboratory, Second Hospital, Jilin University, 218 Ziqiang Street, Jilin, Changchun 130041, P.R. China

E-mail: zhangguizhenjlu@163.com

E-mail: doom99106@163.com

Key words: quantitative polymerase chain reaction, control gene, pregnant females, plasma DNA, normalization

\section{Introduction}

Quantitative polymerase chain reaction (qPCR) is the most fundamental, sensitive and common method used for quantitative analysis of DNA. However, its accuracy is influenced by a number of external and internal factors, including the amount of starting samples, the quality of templates and PCR efficiency (1). At present, using control genes as a standard normalizer is the most common method to minimize the effects (2). Control genes are commonly defined as genes that ubiquitously exist at stable levels in various biological contexts and are used to confirm the presence and content of DNA, as well as quantitatively measure the total DNA in each sample $(3,4)$. However, accumulating evidence indicates that content levels of widely used control genes vary significantly in different independent studies $(5,6)$.

Since the presence of cell-free fetal DNA in maternal plasma and serum was confirmed by the Lo et al (7) study in 1997, there are increasing studies focusing on the utilization of plasma DNA for non-invasive prenatal diagnosis (NIPD). Thus far, plasma DNA analysis is widely studied in numerous NIPD, including fetal gender detection, Rhesus blood group, $\mathrm{D}$ antigen $(\mathrm{RhD})$ status determination, monogenic diseases and chromosomal aneuploidies prenatal diagnosis. To the best of our knowledge, the commonly used control genes for plasma DNA analysis are frequently chosen empirically and without any preliminary evaluation of their suitability. Thus, it is essential to compare and evaluate the content stability of each control gene prior to use for normalization in quantitative analysis of plasma DNA.

The focus of the present study is on the content stability of six commonly used control genes (HBB,TERT, GAPDH, $A L B, A C T B$ and $T R G$ ) in pregnant and non-pregnant plasma DNA using qPCR. The candidate control genes were selected from previous studies on pregnant plasma DNA (8-11). Three common programs, geNorm (12), NormFinder (13) and BestKeeper (14), were used for data analysis. In order to confirm the analysis results, each of the candidate control genes was used as a normalizer to quantitatively measure the $D S C R 3$ gene. The $D S C R 3$ region only exists in chromosome 21 and it is supposed to have the same relative quantity in pregnant 
Table I. Primer sequences, product sizes and PCR efficiency.

\begin{tabular}{|c|c|c|c|c|}
\hline Symbol & Gene name & Primers sequences $\left(5^{\prime} \rightarrow 3^{\prime}\right)$ & $\begin{array}{l}\text { Amplicon } \\
\text { size (bp) }\end{array}$ & $\begin{array}{c}\text { PCR } \\
\text { efficiency }\end{array}$ \\
\hline$H B B$ & $\beta$-globin & $\begin{array}{l}\text { F-GTGCACCTGACTCCTGAGGAGA } \\
\text { R-CCTTGATACCAACCTGCCCAG }\end{array}$ & 101 & 2.58 \\
\hline TERT & Telomerase & $\begin{array}{l}\text { F-GGTGAACCTCGTAAGTTTATGCAA } \\
\text { R-GGCACACGTGGCTTTTCG }\end{array}$ & 97 & 2.00 \\
\hline$G A P D H$ & $\begin{array}{l}\text { Glyceraldehyde-3- } \\
\text { phosphate dehydrogenase }\end{array}$ & $\begin{array}{l}\text { F-GGACTGAGGCTCCCACCTTT } \\
\text { R-GCATGGACTGTGGTCTGCAA }\end{array}$ & 157 & 1.72 \\
\hline$A L B$ & Albumin & $\begin{array}{l}\text { F-TGAAACATACGTTCCCAAAGAGTTT } \\
\text { R-CTCTCCTTCTCAGAAAGTGTGCATAT }\end{array}$ & 80 & 1.79 \\
\hline$A C T B$ & $\beta$-actin & $\begin{array}{l}\text { F-CCTGTACGCCAACACAGTGC } \\
\text { R-ATACTCCTGCTTGCTGATCC }\end{array}$ & 211 & 2.08 \\
\hline$T R G$ & $\mathrm{~T}$ cell receptor $\gamma$ & $\begin{array}{l}\text { F-AGGGTTGTGTTGGAATCAGG } \\
\text { R-CGTCGACAACAAGTGTTGTTCCAC }\end{array}$ & 160 & 1.82 \\
\hline DSCR3 & $\begin{array}{l}\text { Down syndrome } \\
\text { critical region-3 }\end{array}$ & $\begin{array}{l}\text { F-CAGTGCAATGACAGCAGTAT } \\
\text { R-TGGGATCACATCAAGCTAA }\end{array}$ & 141 & 2.11 \\
\hline$S R Y$ & $\begin{array}{l}\text { Gender-determining } \\
\text { region } \mathrm{Y}\end{array}$ & $\begin{array}{l}\text { F-AAAGGCAACGTCCAGGATAGAG } \\
\text { R-CCACTGGTATCCCAGCTGCT }\end{array}$ & 137 & 2.19 \\
\hline
\end{tabular}

bp, basepair; PCR, polymerase chain reaction.

and non-pregnant groups of normal females $(15,16)$. The result may reveal the optimal control gene selections for further quantitative studies on plasma DNA from pregnant females.

\section{Materials and methods}

Plasma sample collection and DNA extraction. A total of $2 \mathrm{ml}$ peripheral blood donated from 18 pregnant females (gestational age, 12.87 \pm 1.25 weeks) and 18 non-pregnant volunteers was collected. A form of consent was obtained from each volunteer and the experiment was approved by the Ethical Committee of Second Hospital, Jilin University (Jilin, China). The blood samples were anti-coagulated by EDTA. The plasma supernatant was separated from the entire blood by centrifugation at $2,000 \mathrm{xg}$ for $20 \mathrm{~min}$ at room temperature, followed by further centrifugation at $12,000 \mathrm{x} \mathrm{g}$ for $5 \mathrm{~min}$ to remove the residual intact cells. The supernatant was collected carefully. DNA was extracted from $350 \mu \mathrm{l}$ plasma from each sample by the QIAamp DNA mini kit (Qiagen, Hilden, Germany) following the manufacturer's protocol. The whole process was performed within $4 \mathrm{~h}$ of the withdrawal time.

qPCR analysis. qPCR was carried out using Roche LightCycler 480 [Roche Diagnostics (Schweiz) AG, Risch, Switzerland]. The primers of the control (HBB,TERT, GAPDH, $A L B, A C T B$ and $T R G$ ) and two target genes (DSCR3 and $S R Y)$ were synthesized by Sangon Biotech Shanghai Co., Ltd., (Shanghai, China) (Table I).

The reactions were performed in a $20 \mu$ l volume containing 8 ng DNA using the All-in-One qPCR Mix kit (GeneCopodia, Inc., Rockville, MD, USA) following the protocol. The amplification was as follows: An initial step of $95^{\circ} \mathrm{C}$ for $10 \mathrm{~min}$,
50 cycles of $95^{\circ} \mathrm{C}$ for $15 \mathrm{sec}, 58^{\circ} \mathrm{C}$ for $15 \mathrm{sec}$ and $72^{\circ} \mathrm{C}$ for $30 \mathrm{sec}$. Each assay was performed in triplicate. qPCR results were subjected to $1 \%$ agarose gel electrophoresis. To estimate the efficiencies of amplification, a standard curve was generated for each primer pair based on four points of serial 2-fold DNA dilution. The efficiencies were calculated using the slope of the calibration curve following the equation: $E=2^{-1 / s l o p e}$.

Data analysis. Microsoft Excel was used to calculate the mean and standard deviation (SD) values. The content stabilities of the six candidate-control genes were assessed by three commonly used programs: geNorm, NormFinder and BestKeeper, as described in their manuals. geNorm calculates a gene content stability measure $(\mathrm{M})$ and pairwise variation $(\mathrm{V})$ parameter. Lower $\mathrm{M}$ values represent higher content stability. $\mathrm{V}$ is calculated to determine the minimal number of control genes required. When $\mathrm{V}<0.15$, the number of control genes is enough for valid normalization. NormFinder computes inter- and intra-group content stability values by an analysis of variance-based model. Lower value indicates higher content stabilities. BestKeeper analyses content stability based on SD and coefficient of correlation ( $r$ ) of all the candidate control genes. The genes with SD $>1.00$ are suggested to be considered unreliable as a stable control gene and the remaining genes are ranked according to their $r$ values, with a higher $r$ value indicating higher stability. All the analyses were performed separately for the following three groups: Pregnant, non-pregnant and total sample (pregnant and non-pregnant) groups.

Control gene validation. DSCR3 was used as the target gene in order to validate the control genes for normalization of relative quantity in the pregnant and non-pregnant groups (17). The 
A

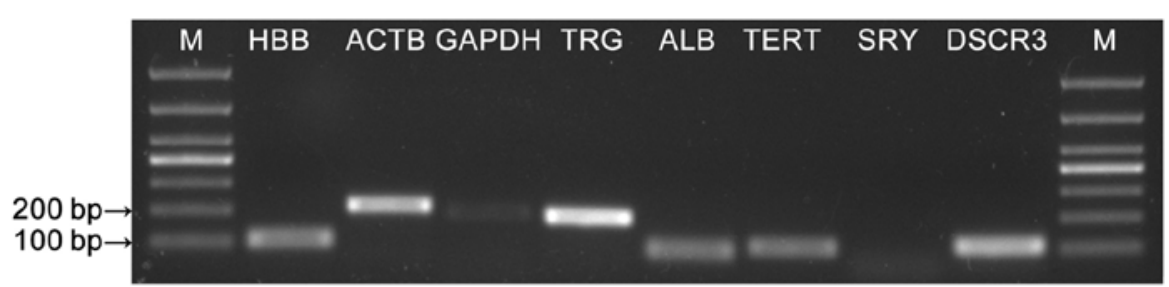

B
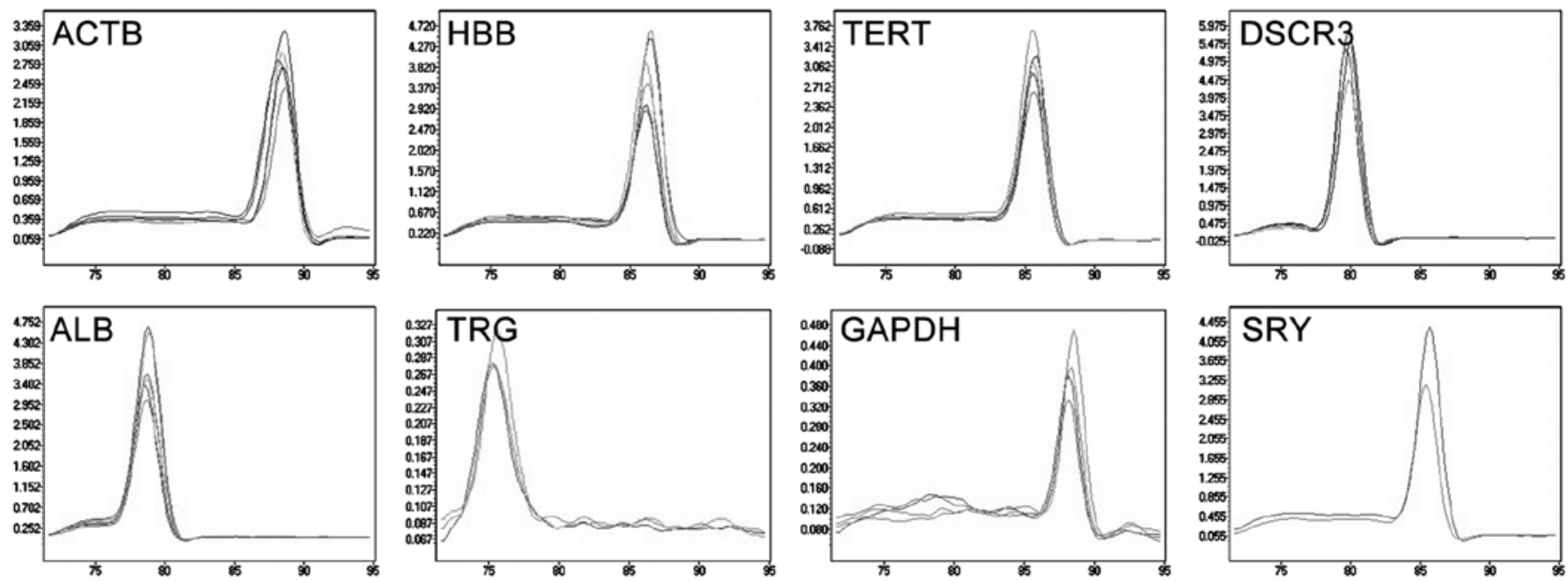

Figure 1. Specificity of primers and amplicon length. (A) $1 \%$ agarose gel electrophoresis of amplified fragments. M, DNA marker DL 1000. (B) Melting curve of six control genes and two target genes.
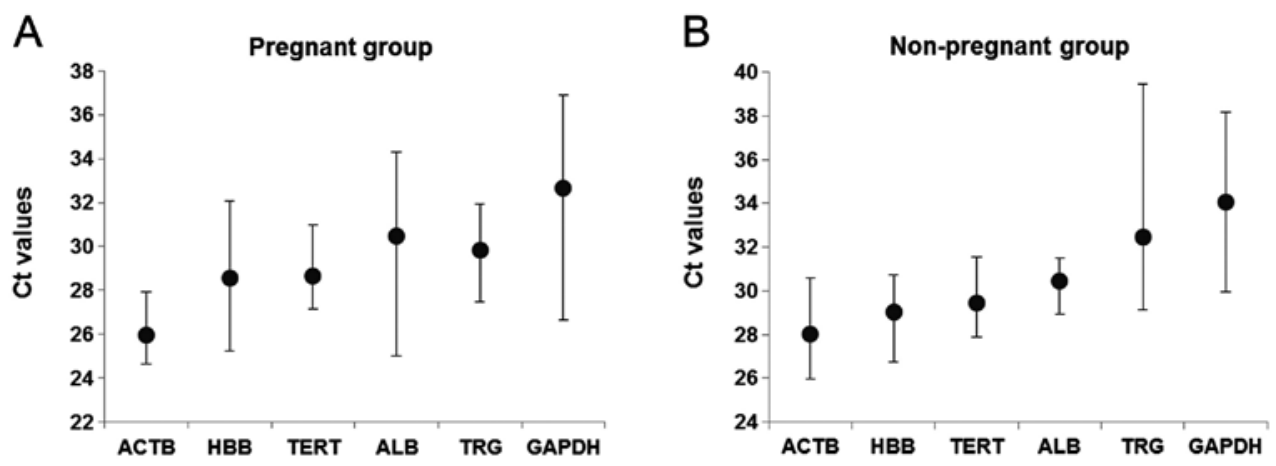

Figure 2. Mean Ct values of the candidate control genes in (A) pregnant $(n=18)$ and $(B)$ non-pregnant $(n=18)$ group samples. The circle represents the arithmetic mean; the bar indicates the minimal to maximal $\mathrm{Ct}$ value.

relative quantity in each sample was normalized by each of the six control genes and the most stable combination recommended by geNorm and NormFinder independently, using the $2^{-\Delta \Delta \mathrm{Ct}}$ method (18). $S R Y$ is only presented in pregnant females carrying male fetuses (19), and was used to detect whether or not the extracted DNA was contaminated with exogenous DNA.

\section{Results}

Amplification performance of primers. The qPCR amplification product was detected in $1 \%$ agarose gel electrophoresis. The results showed clear bands with expected size and no primer dimers (Fig. 1A). One single peak was obtained in each amplification reaction during the analysis of the melting curves; this confirmed the specific amplification of primers (Fig. 1B). The efficiencies of the primers are listed in Table I. SRY was only amplified in the pregnant group, indicating that there was no exogenous DNA contamination.

Amplification profile of candidate control genes. The amplification profile of the candidate control genes was estimated as $\mathrm{Ct}$ values. Fig. 2 shows the mean $\mathrm{Ct}$ values of each gene in the pregnant and non-pregnant groups. The $\mathrm{Ct}$ values of the groups varied between 25.99 to 32.66 for the pregnant group (Fig. 2A) and 28.02 to 34.09 for the non-pregnant group (Fig. 2B). $A C T B$ exhibited the lowest $\mathrm{Ct}$ value (mean $\pm \mathrm{SD}$ is $25.99 \pm 0.99$ and 28.02 \pm 1.86 ) and $G A P D H$ exhibited the highest $\mathrm{Ct}$ value (mean $\pm \mathrm{SD}$ is $32.66 \pm 3.21$ and $34.09 \pm 2.92$ ) in the two groups respectively. In the pregnant group, $G A P D H$ is the most variable with a high SD value (3.21), whereas $A C T B$ had the lowest 
Table II. Rank of six candidate control genes in order of their quantity stability calculated by NormFinder.

\begin{tabular}{|c|c|c|c|c|c|c|}
\hline \multirow[b]{2}{*}{ Rank } & \multicolumn{2}{|c|}{ Total sample } & \multicolumn{2}{|c|}{ Pregnant group } & \multicolumn{2}{|c|}{ Non-pregnant group } \\
\hline & Gene & Stability value & Gene & Stability value & Gene & Stability value \\
\hline 1 & TERT & 0.340 & $A C T B$ & 0.115 & $H B B$ & 0.318 \\
\hline 2 & ACTB & 0.418 & TERT & 0.299 & $A L B$ & 0.419 \\
\hline 3 & $H B B$ & 0.462 & $T R G$ & 0.439 & $T E R T$ & 0.782 \\
\hline 4 & $G A P D H$ & 0.552 & $A L B$ & 0.928 & ACTB & 0.820 \\
\hline 5 & $A L B$ & 0.577 & $H B B$ & 1.218 & GAPDH & 0.930 \\
\hline 6 & $T R G$ & 0.771 & $G A P D H$ & 2.042 & $T R G$ & 2.360 \\
\hline
\end{tabular}

A

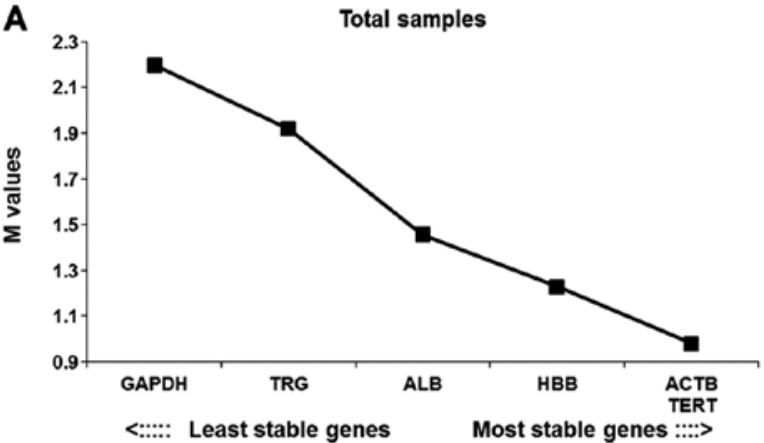

C

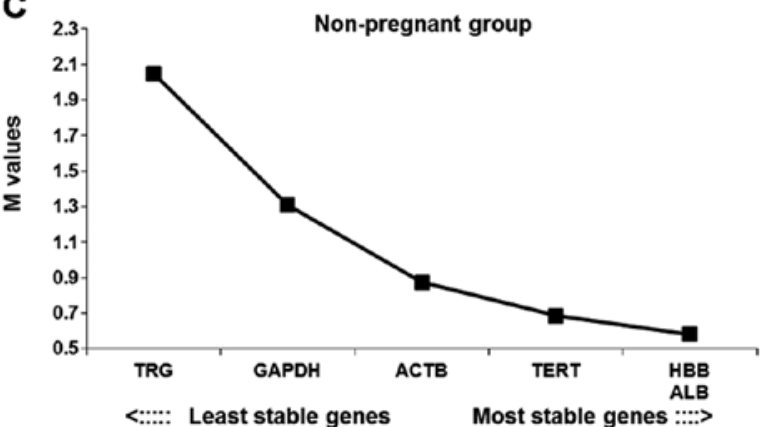

B

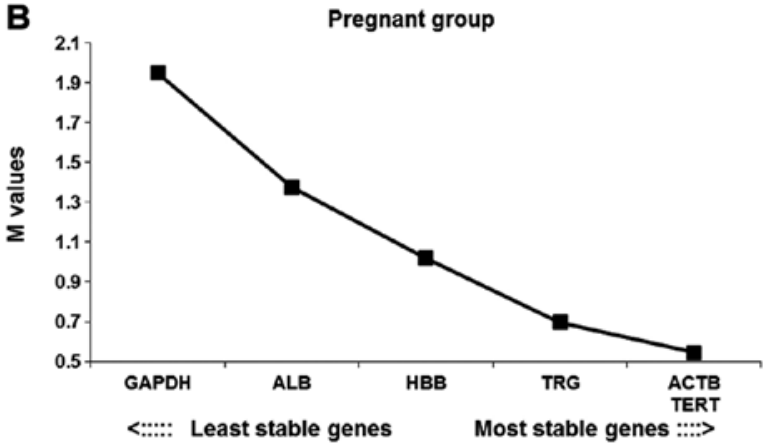

D

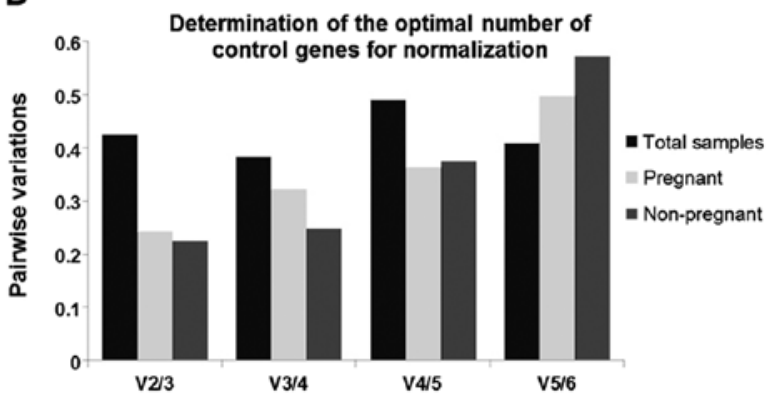

Figure 3. Stability values of the candidate control genes analyzed by geNorm. Expression stability measures (M) of the six control genes analyzed and the quantity stability was plotted in the (A) total samples, (B) pregnant and (C) non-pregnant groups. The x-axis from left to right indicates the ranking of the genes according to their stability; lower M values indicate higher stability. (D) Determination of the optimal number of control genes for normalization was conducted. The program calculates the normalization factor from at least two genes at which the variable, V, defines the pair-wise variation between two sequential normalization factors.

SD values (0.99). In the non-pregnant group, $T R G$ was the most variable with a high SD value (4.13), whereas $A L B$ had the lowest SD values (1.19). There was no significant difference of the $\mathrm{Ct}$ values between maternal- and fetal-derived DNA in each gene.

geNorm analysis. The geNorm analysis result revealed that $A C T B$ and TERT were the most stable genes and GAPDH was the least stable among the total samples (Fig. 3A). Similar results were obtained in the pregnant group (Fig. 3B). In the non-pregnant group, $H B B$ and $A L B$ were the most stable genes and $T R G$ was the least stable (Fig. 3C). None of the $\mathrm{V}$ values were below the cut-off value (Fig. 3D) indicating that there was no optimal combination number of control genes for normalization.
NormFinder analysis. The results of the NormFinder analysis showed that $A C T B$ and TERT were the top two content stable genes in the total and pregnant groups, whereas $H B B$ and $A L B$ were the top two genes in the non-pregnant group (Table II). GAPDH and TRG were the least stable genes in the pregnant and non-pregnant groups, respectively, and $T R G$ was also considered as the least stable in the total group. The best combination of two genes for total sample analysis was ACTB and TERT, and the stability value $(0.224)$ was lower than TERT (0.340). This indicated that the combination of these two genes provide higher stability than using TERT alone.

BestKeeper analysis. According to BestKeeper analysis, when considering the total samples, TERT was found to be the optimal control gene with $\mathrm{SD}<1.00$ and the highest $\mathrm{r}$ value (0.870). In 
Table III. Descriptive statistics of six candidate control genes based on their cycle threshold values as calculated by BestKeeper.

\begin{tabular}{|c|c|c|c|c|c|c|c|}
\hline Group & $\mathrm{CP}$ data & $A C T B$ & $H B B$ & TERT & $A L B$ & $T R G$ & $G A P D H$ \\
\hline \multirow[t]{5}{*}{ Total samples } & geo Mean $(\mathrm{CP})$ & 26.74994 & 28.67918 & 28.94395 & 30.42784 & 30.74505 & 33.09142 \\
\hline & $\operatorname{Min}(\mathrm{CP})$ & 24.63311 & 25.21569 & 27.16459 & 25.00278 & 27.47232 & 26.64072 \\
\hline & $\operatorname{Max}(\mathrm{CP})$ & 30.58614 & 32.06806 & 31.57339 & 34.2869 & 39.44698 & 38.16773 \\
\hline & $\mathrm{SD}( \pm \mathrm{CP})$ & 1.310503 & 1.699849 & 0.999535 & 1.369684 & 1.955511 & 2.533179 \\
\hline & coeff. of corr. (r) & 0.853 & 0.754 & 0.870 & 0.776 & 0.784 & 0.774 \\
\hline \multirow[t]{5}{*}{ Pregnant } & geo Mean (CP) & 25.96939 & 28.4677 & 28.61777 & 30.40847 & 29.79071 & 32.51344 \\
\hline & $\operatorname{Min}(\mathrm{CP})$ & 24.63311 & 25.21569 & 27.16459 & 25.00278 & 27.47232 & 26.64072 \\
\hline & $\operatorname{Max}(\mathrm{CP})$ & 27.91232 & 32.06806 & 30.97218 & 34.28690 & 31.92536 & 36.89494 \\
\hline & $\mathrm{SD}( \pm \mathrm{CP})$ & 0.76351 & 1.804439 & 0.877834 & 1.575063 & 1.160367 & 2.65516 \\
\hline & coeff. of corr. (r) & 0.954 & 0.711 & 0.887 & 0.888 & 0.852 & 0.644 \\
\hline \multirow[t]{5}{*}{ Non-pregnant } & geo Mean (CP) & 27.96496 & 28.99936 & 29.44021 & 30.45691 & 32.23419 & 33.97771 \\
\hline & $\operatorname{Min}(\mathrm{CP})$ & 25.98068 & 26.73664 & 27.9093 & 28.95515 & 29.13656 & 29.93401 \\
\hline & $\operatorname{Max}(\mathrm{CP})$ & 30.58614 & 30.70807 & 31.57339 & 31.51242 & 39.44698 & 38.16773 \\
\hline & $\mathrm{SD}( \pm \mathrm{CP})$ & 1.545731 & 1.419053 & 0.983466 & 1.066481 & 3.279869 & 2.360286 \\
\hline & coeff of corr $(r)$ & 0.814 & 0.920 & 0.815 & 0.951 & 0.785 & 0.948 \\
\hline
\end{tabular}

$\mathrm{CP}$, cycle threshold; geo Mean $(\mathrm{CP})$, geometric mean $(\mathrm{CP})$; min, $\max (\mathrm{CP})$, extreme values of $(\mathrm{CP})$; SD $( \pm \mathrm{CP})$, standard deviation $(\mathrm{CP})$; coeff of corr (r), pairwise correlation coefficient.

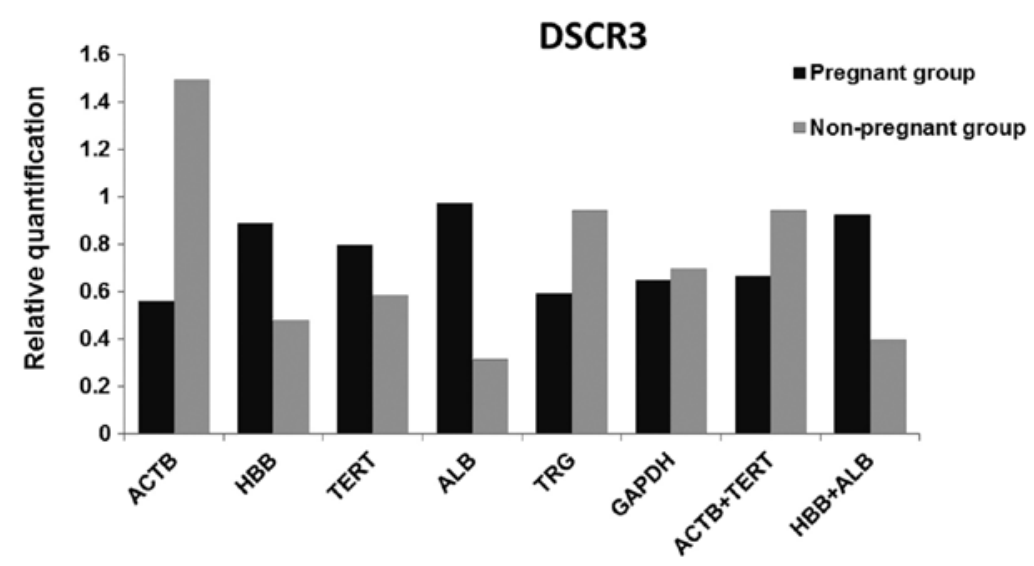

Figure 4. Relative quantities of the target gene DSCR3 $(\mathrm{n}=36)$ in the plasma DNA upon different normalization approaches. Quantitative polymerase chain reaction (qPCR) data were normalized by six single control genes and two different combinations.

the pregnant group, $A C T B$ and TERT were acceptable with $\mathrm{SD}<1.00$, whereas $A C T B$ had a higher $\mathrm{r}$ value $(0.954)$ and was considered to be the most optimal control gene. In the non-pregnant group, TERT was the only gene with $\mathrm{SD}<1.00$, but $A L B$ had the highest $\mathrm{r}$ value (0.951). Although the SD of $A L B$ was higher than $1.00(\mathrm{SD}=1.07)$, it was still considered to be a reliable control gene, similar to TERT (Table III). GAPDH and $T R G$ were the least stable genes as shown by the results of geNorm and NormFinder in the pregnant and non-pregnant groups.

Validation of control genes. In order to verify the results of the control genes from geNorm, NormFinder and BestKeeper, the relative quantities of DSCR3 were determined using six candidate control genes and the combinations recommended by geNorm $(A C T B+T E R T)$ and NormFinder $(H B B+A L B)$ were the normalizers (Fig. 4). GAPDH had the minimum difference between the two groups, followed by TERT. ACTB had the largest difference, although it was ranked as one of the top two in all three algorithms. TERT combined with $A C T B$ provided a smaller difference between the two groups compared to $A L B+H B B$.

\section{Discussion}

The discovery of cell-free fetal DNA in maternal plasma has become a primary target for NIPD (7). In healthy gravidae, fetal DNA can be detected in maternal plasma as early as the seventh week after conception (20), and it increases with the pregnancy progresses (10), reaches the plateau in the ensuing three months, is promptly cleared from maternal plasma and disappears within $2 \mathrm{~h}$ of delivery (21). These properties caused 
plasma DNA to be the optimal material for NIPD. Thus far, qPCR is the most fundamental, sensitive and accurate method, widely used in studies of maternal plasma DNA. Due to its low cost and ease of use, a number of diseases, including gender determination (22-24), $\beta$-thalassemia (25-27), rhesus fetal blood group genotyping (28-30) and aneuploidies diseases (31), have been successfully diagnosed by qPCR. Although it is an extremely useful technique, there are challenges concerned with its use. The most important is normalization with an accurate, reliable control gene. To avoid the incorrect analysis results caused by pipetting errors, inhibitory compounds, quality of starting material or other systematic errors in qPCR (32), control genes should be stably contained in pregnant and non-pregnant female plasma. Ideally, control genes in plasma should not be influenced or regulated by pregnancy conditions, stress response, stimulation or any other physiological or pathological states between different individuals $(4,33)$. However, there is accumulating evidence indicating that content levels of widely used control genes varies significantly in different independent studies, for example, $B 2 M, A C T B$ and $S D H A$ showed significant variation in expression levels in human epileptogenic brain tissues (34), and the single-copy DNA control gene $H B B$, which is used for representing the cell number, has been proved to not be the most reliable control gene (3). Therefore, it has become indispensable to normalize the control gene quantity levels and determine reliable control genes prior to any qPCR relative quantitative analysis. To the best of our knowledge, this is the first study to evaluate the content stability of control genes commonly used in the plasma DNA from pregnant and non-pregnant females. In the present study, the samples in the second trimester of the gestational age were selected, as in this stage the content of plasma DNA is stable. Six commonly used control genes (HBB, TERT, $G A P D H, A L B, A C T B$ and $T R G$ ) were analyzed by qPCR of the plasma DNA from pregnant and non-pregnant females. Three common statistical algorithms (geNorm, NormFinder and BestKeeper) were used for data analysis and DSCR3 was used to confirm the data analysis results.

On the basis of the results obtained from the three algorithms, the rank of the candidate genes stability was slightly different. These variations were possibly caused by different calculation algorithms $(35,36)$ and indicated different features of the correlations between these control genes. Among the six candidate control genes, $A C T B$ and TERT in the total samples and pregnant group, and $H B B$ and $A L B$ in the non-pregnant group showed the highest stability. This conclusion is consistent with the $\mathrm{Ct}$ values. $A C T B, T E R T$ and $T R G$ had the lowest $\mathrm{SD}(0.99,1.16$ and 1.43$)$ of the $\mathrm{Ct}$ values in the pregnant group; $A L B, T E R T$ and $H B B$ had the lowest SD $(1.19,1.25$ and 1.64) in the non-pregnant group. By contrast, $G A P D H$ was unanimously affirmed as the least stable gene by the three algorithms in the pregnant group, as was $T R G$ in the non-pregnant group. This corresponded to their high SD (3.21 and 4.13, respectively) for the $\mathrm{Ct}$ values, which means that they clearly vary.

In order to evaluate the exactitude of the control genes recommended by the three algorithms, the candidate control genes were used as a normalizer to detect the relative levels of the DSCR3 gene. The DSCR3 region only exists in chromosome 21 , which is supposed to have the same relative quantity in the plasma DNA from pregnant and non-pregnant females. The content variance between the pregnant and non-pregnant groups was performed at maximum when using $A C T B$ as the control gene, but minimum when using $G A P D H$. There is a slight discrepancy between the DSCR3 evaluation and algorithm results. When using TERT as the normalizer, the content variance is within the tolerable range. When combining more than one control gene as the normalizer, the best combination chosen was $A C T B+T E R T$, suggested by geNorm, and $H B B+A L B$ from NormFinder. The result reveals that $A C T B+T E R T$ obtain an improved result compared to using TERT alone.

The optimal number of control genes for normalization was indicated by the $\mathrm{V}$ value below the cut-off of 0.15 , as shown in geNorm (12). However, as the result from geNorm showed, there was no optimal combination of the selected control genes below the cut-off value. It has been suggested that when conditions permit, three of the most stable control genes could be used instead of a single gene $(37,38)$.

Furthermore, it is of note that the concentration of plasma DNA in plasma is extremely low (21) and highly originates from the apoptosis process $(39,40)$. These characteristics influence the amplification efficiency of plasma DNA. For example, firstly, the amplificon sizes should be short enough, as the longer the template of the target gene is, the more opportunities there are to be digested in the apoptosis process, which reduces the effective templates. Secondly, the succesful amplification of every single target gene from plasma DNA cannot be guaranteed. There are increasing studies focusing further on the clinical application of plasma DNA, which is required for NIPD. However, to the best of our knowledge, all the control genes used in plasma DNA analysis are chosen by experience, and no evaluation has been performed to confirm the content stability of these control genes in the plasma DNA from pregnant and non-pregnant females. The present study validated the most content stable control genes at the second trimester of gestational age, which can be used as a criterion in subsequent studies.

In conclusion, the present study indicated that the content stability of control genes used for DNA showed significant variation in pregnant and non-pregnant plasma DNA. Every qPCR DNA study should commence with the selection of an appropriate control gene individually. According to the study, TERT and the combination of $A C T B$ and TERT permit an efficient normalization for DNA quantitation using qPCR in pregnant and non-pregnant plasma, whereas GAPDH and TRG were proved to be the least reliable control genes.

\section{Acknowledgements}

The present study was supported by the Project supported by the Key Foundation of Jilin Provincial Science and Technology Department, China (nos. 20130727038YY and 20100942) and the Jilin Provincial Development and Reform Commission, China (no. 20101928).

\section{References}

1. Zhong Q, Zhang Q, Wang Z, et al: Expression profiling and validation of potential reference genes during Paralichthys olivaceus embryogenesis. Mar Biotechnol (NY) 10: 310-318, 2008.

2. Dheda K, Huggett JF, Bustin SA, Johnson MA, Rook G and Zumla A: Validation of housekeeping genes for normalizing RNA expression in real-time PCR. Biotechniques 37: 112-114, 116, 118-119, 2004. 
3. Steinau M, Rajeevan MS and Unger ER: DNA and RNA references for qRT-PCR assays in exfoliated cervical cells. J Mol Diagn 8: 113-118, 2006.

4. Radonic A, Thulke S, Mackay IM, Landt O, Siegert W and Nitsche A: Guideline to reference gene selection for quantitative real-time PCR. Biochem Biophys Res Commun 313: 856-862, 2004.

5. Cordoba EM, Die JV, González-Verdejo CI, Nadal S and Román B: Selection of reference genes in Hedysarum coronarium under various stresses and stages of development. Anal Biochem 409: 236-243, 2011.

6. Guénin S, Mauriat M, Pelloux J, Van Wuytswinkel O, Bellini C and Gutierrez L: Normalization of qRT-PCR data: the necessity of adopting a systematic, experimental conditions-specific, validation of references. J Exp Bot 60: 487-493, 2009.

7. Lo YM, Corbetta N, Chamberlain PF, et al: Presence of fetal DNA in maternal plasma and serum. Lancet 350: 485-487, 1997

8. Alizadeh M, Bernard M, Danic B, et al: Quantitative assessment of hematopoietic chimerism after bone marrow transplantation by real-time quantitative polymerase chain reaction. Blood 99 : 4618-4625, 2002.

9. Bianchi DW, Avent ND, Costa JM and van der Schoot CE: Noninvasive prenatal diagnosis of fetal Rhesus D: ready for Prime (r) Time. Obstet Gynecol 106: 841-844, 2005.

10. Lo YM, Tein MS, Lau TK, et al: Quantitative analysis of fetal DNA in maternal plasma and serum: implications for noninvasive prenatal diagnosis. Am J Hum Genet 62: 768-775, 1998.

11. Picchiassi E, Coata G, Fanetti A, Centra M, Pennacchi L and Di Renzo GC: The best approach for early prediction of fetal gender by using free fetal DNA from maternal plasma. Prenat Diagn 28: 525-530, 2008.

12. Vandesompele J, De Preter K, Pattyn F, et al: Accurate normalization of real-time quantitative RT-PCR data by geometric averaging of multiple internal control genes. Genome Biol 3: RESEARCH0034, 2002.

13. Andersen CL, Jensen JL and Ørntoft TF: Normalization of real-time quantitative reverse transcription-PCR data: a model-based variance estimation approach to identify genes suited for normalization, applied to bladder and colon cancer data sets. Cancer Res 64: 5245-5250, 2004.

14. Pfaffl MW, Tichopad A, Prgomet C and Neuvians TP Determination of stable housekeeping genes, differentially regulated target genes and sample integrity: BestKeeper-Excel-based tool using pair-wise correlations. Biotechnol Lett 26: 509-515, 2004.

15. Helmy SM, Ismail S, Bassiouni R and Gaber KR: Sensitivity of DCSR3/GAPDH ratio using quantitative real-time PCR in the rapid prenatal diagnosis for down syndrome. Fetal Diagn Ther 25: 220-223, 2009 .

16. Hu Y, Zheng M, Xu Z, Wang X and Cui H: Quantitative real-time PCR technique for rapid prenatal diagnosis of Down syndrome. Prenat Diagn 24: 704-707, 2004.

17. Papageorgiou EA, Karagrigoriou A, Tsaliki E, Velissariou V, Carter NP and Patsalis PC: Fetal-specific DNA methylation ratio permits noninvasive prenatal diagnosis of trisomy 21. Nat Med 17: 510-513, 2011.

18. Livak KJ and Schmittgen TD: Analysis of relative gene expression data using real-time quantitative PCR and the 2(-Delta Delta C(T)) Method. Methods 25: 402-408, 2001.

19. Honda H, Miharu N, Ohashi Y, et al: Fetal gender determination in early pregnancy through qualitative and quantitative analysis of fetal DNA in maternal serum. Hum Genet 110: 75-79, 2002.

20. Galbiati S, Smid M, Gambini D, et al: Fetal DNA detection in maternal plasma throughout gestation. Hum Genet 117: 243-248, 2005.

21. Lo YM, Zhang J, Leung TN, Lau TK, Chang AM and Hjelm NM: Rapid clearance of fetal DNA from maternal plasma. Am J Hum Genet 64: 218-224, 1999.
22. Aghanoori MR, Vafaei $H$, Kavoshi H, Mohamadi $S$ and Goodarzi HR: Sex determination using free fetal DNA at early gestational ages: a comparison between a modified mini-STR genotyping method and real-time PCR. Am J Obstet Gynecol 207: e1-e8, 2012.

23. Fernández-Martínez FJ, Galindo A, Garcia-Burguillo A, et al: Noninvasive fetal sex determination in maternal plasma: a prospective feasibility study. Genet Med 14: 101-106, 2012.

24. Lim JH, Park SY, Kim SY, et al: Effective detection of fetal sex using circulating fetal DNA in first-trimester maternal plasma. FASEB J 26: 250-258, 2012.

25. Yenilmez ED, Tuli A and Evruke IC: Noninvasive prenatal diagnosis experience in the Cukurova Region of Southern Turkey: detecting paternal mutations of sickle cell anemia and $\beta$-thalassemia in cell-free fetal DNA using high-resolution melting analysis. Prenat Diagn 33: 1054-1062, 2013.

26. Gao T, Nie Y and Guo J: Hypermethylation of the gene LARP2 for noninvasive prenatal diagnosis of $\beta$-thalassemia based on DNA methylation profile. Mol Biol Rep 39: 6591-6598, 2012

27. Gao T, Nie Y, Hu H and Liang Z: Hypermethylation of IGSF4 gene for noninvasive prenatal diagnosis of thalassemia. Med Sci Monit 18: BR33-BR40, 2012.

28. Scheffer PG, van der Schoot CE, Page-Christiaens GC and de Haas M: Noninvasive fetal blood group genotyping of rhesus D, $\mathrm{c}, \mathrm{E}$ and of $\mathrm{K}$ in alloimmunised pregnant women: evaluation of a 7-year clinical experience. BJOG 118: 1340-1348, 2011.

29. Chinen PA, Nardozza LM, Martinhago CD, et al: Noninvasive determination of fetal rh blood group, D antigen status by cell-free DNA analysis in maternal plasma: experience in a Brazilian population. Am J Perinatol 27: 759-762, 2010.

30. Gutensohn K, Müller SP, Thomann K, et al: Diagnostic accuracy of noninvasive polymerase chain reaction testing for the determination of fetal rhesus $\mathrm{C}, \mathrm{c}$ and $\mathrm{E}$ status in early pregnancy. BJOG 117: 722-729, 2010

31. Della Ragione F, Mastrovito P, Campanile C, et al: Differential DNA methylation as a tool for noninvasive prenatal diagnosis (NIPD) of X chromosome aneuploidies. J Mol Diagn 12: 797-807, 2010.

32. Bustin S, Benes V, Nolan T and Pfaffl MW: Quantitative real-time RT-PCR-a perspective. J Mol Endocrinol 34: 597-601, 2005.

33. Peters IR, Peeters D, Helps CR and Day MJ: Development and application of multiple internal reference (housekeeper) gene assays for accurate normalisation of canine gene expression studies. Vet Immunol Immunopathol 117: 55-66, 2007.

34. Wierschke S, Gigout S, Horn P, et al: Evaluating reference genes to normalize gene expression in human epileptogenic brain tissues. Biochem Biophys Res Commun 403: 385-390, 2010.

35. Chang E, Shi S, Liu J, et al: Selection of reference genes for quantitative gene expression studies in Platycladus orientalis (Cupressaceae) Using real-time PCR. PLoS One 7: e33278, 2012

36. Brugè $F$, Venditti E, Tiano L, Littarru G and Damiani E: Reference gene validation for qPCR on normoxia-and hypoxia-cultured human dermal fibroblasts exposed to UVA: Is $\beta$-actin a reliable normalizer for photoaging studies? J Biotechnol 156: 153-162, 2011.

37. Liman M, Wenji W, Conghui L, et al: Selection of reference genes for reverse transcription quantitative real-time PCR normalization in black rockfish (Sebastes schlegeli). Mar Genomics 11: $67-73,2013$

38. Xu Y, Zhu X, Gong Y, Xu L, Wang Y and Liu L: Evaluation of reference genes for gene expression studies in radish (Raphanus sativus L.) using quantitative real-time PCR. Biochem Biophys Res Commun 424: 398-403, 2012.

39. Alberry M, Maddocks D, Jones M, et al: Free fetal DNA in maternal plasma in anembryonic pregnancies: confirmation that the origin is the trophoblast. Prenat Diagn 27: 415-418, 2007.

40. Chan KC, Zhang J, Hui AB, et al: Size distributions of maternal and fetal DNA in maternal plasma. Clin Chem 50: 88-92, 2004. 